\title{
Propostas metodolóxicas activas en dous Programas de Posgrao da UDC: Aprendizaxe cooperativa, Flipped Classroom e Entornos Persoais de Aprendizaxe
}

\author{
Lasa-Álvarez, Begoña'; Lorenzo-Modia, María Jesús² \\ ${ }^{1}$ Universidade da Coruña, Facultade de Ciencias da Educación, \\ http://orcid.org/0000-0002-8045-3557 \\ ${ }^{2}$ Universidade da Coruña, Facultade de Filoloxía, \\ https://orcid.org/0000-0002-3524-9477
}

\section{RESUMO}

Neste traballo preséntase unha proposta para a implementación na aula de varios métodos de ensinoaprendizaxe activos en programas de posgrao da Universidade da Coruña impartidos por integrantes do Grupo de Innovación Docente en Estudos ingleses e irlandeses. Este grupo traballou e segue a traballar de forma continuada incluindo na súa práctica docente diversas metodoloxías nas que o alumnado sexa 0 centro da aula e axente activo da súa aprendizaxe. 0 profesorado adquire así un novo rol como guía e facilitador das experiencias docentes. Exporemos a utilización de estratexias das metodoloxías de aprendizaxe cooperativa e de aula invertida ou flipped classroom para que 0 alumnado asimile e se familiarice de xeito práctico con estas dúas praxes docentes. Polo tanto, mostraranse as actividades realizadas na materia de Métodoloxía de ensino-aprendizaxe da lingua estranxeira no Mestrado de Secundaria da Universidade da Coruña, e a continuación, presentarase un proxecto deseñado para a materia Modelos de Interpretación Literario-cultural do Mestrado Interuniversitario en Estudos Ingleses Avanzados. Neste caso, trátase de utilizar técnicas relacionadas con entornos persoais de aprendizaxe (PLE) para a selección, organización e creación de contidos dixitais incluidos na materia mencionada. A modo de conclusión, sinalaremos os beneficios obtidos como fundamento da nosa aposta polas metodoloxías activas na docencia universitaria, nas que continuaremos a afondar nos vindeiros cursos.

PALABRAS CLAVE: Metodoloxías activas, aprendizaxe cooperativa, aula invertida, entorno persoal de aprendizaxe (PLE) 


\section{CITA RECOMENDADA:}

Lasa-Álvarez, Begoña; Lorenzo-Modia, María Jesús (2020): Propostas metodolóxicas activas en dous Programas de Posgrao da UDC: Aprendizaxe cooperativa, Flipped Classroom e Entornos Persoais de Aprendizaxe. En De la Torre Fernández, E. (ed.) (2020). Contextos universitarios transformadores: Boas prácticas no marco dos GID. IV Xornadas de Innovación Docente. Cufie. Universidade da Coruña. A Coruña (págs. 121-134).

DOI capítulo: https://doi.org/10.17979/spudc. 9788497497756.121

DOl libro: https://doi.org/10.17979/spudc.9788497497756

\section{ABSTRACT}

This paper presents a proposal for the implementation of several active teaching-learning methods in the classrooms of two postgraduate programs at the University of A Coruña, by members of the teaching innovation group in English and Irish studies. This group has worked and continues to work with various student-centred methodologies in the teaching practice, in which students are also active agents of their learning process. Teachers, thus, acquire a new role as guides and facilitators of teaching experiences. We will foster the use of strategies of cooperative learning and flipped classroom, so that students can assimilate and become familiar with these two methodologies. Therefore, we will describe the tasks carried out in the subject of Teaching-Learning Methodology of the foreign language in the Master's Degree in Secondary Education. Besides, we will show a project designed for the subject Models of literary and cultural interpretation of the interuniversity Master's degree in Advanced English Studies. In this case, techniques related to personal learning environments (PLE) will be used by the students for the selection, organization and creation of digital contents included in the aforementioned subject. As a conclusion, we will point out the benefits obtained in this experience as the basis for our commitment to employing active methodologies with postgraduate students. Our content is to maintain and deepen the implementation of these methodologies in the coming years.

KEY WORDS: Active methodologies, cooperative learning, flipped classroom, personal learning environment (PLE) 


\section{INTRODUCCIÓN}

Entre os eixos temáticos propostos para estas Xornadas, elixiuse o primeiro deles, o que se centra en metodoloxías activas, dado que se trata dunha liña de actuación na que este grupo traballou e segue a traballar de forma continuada. Na nosa práctica docente temos implementado diversas metodoloxías nas que 0 alumnado é 0 centro da aula e axente activo da súa aprendizaxe. 0 profesorado adquire así un novo rol como guía e facilitador das experiencias docentes, e actúa como modelo, apoio, asesor e proveedor de feedback (Ur, 2015). Ademais, como establecen McLaren e Madrid (2005), ao utilizar estes enfoques metodolóxicos 0 alumnado participa na selección e xestión das actividades, que adoitan a ser desenvolvidas en grupo. Como consecuencia disto, a docencia oriéntase máis cara á creatividade e os resultados avalíanse mediante ferramentas novas ou alternativas, e non coas tradicionais, como exames e tests. Finalmente, grazas a este tipo de metodoloxías activas, promóvese a motivación intrínseca, a interdiciplinaiedade e a transversalidade na aula. E con isto as experiencias de ensino-aprendizaxe do alumnado esténdense máis aló da aula e continúan na súa vida cotiá.

No traballo que aquí se presenta, exporemos en primeiro lugar unha experiencia realizada na materia de Metodoloxía do ensino-aprendizaxe da lingua estranxeira (Cod. 437923) no Mestrado Universitario en Profesorado de Educación Secundaria Obrigatoria e Bacharelato, Formación Profesional e Ensinanza de Idiomas que se imparte na Facultade de Ciencias da Educación da Universidade da Coruña. A súa carga docente é de 21 horas e 3 créditos ECTS. Dende 0 curso 2018/2019 veñen utilizándose unha serie de estratexias de dous metodoloxías, aprendizaxe cooperativa e aula invertida ou flipped classroom, coas que o alumnado poida asimilar e familiarizarse de xeito práctico coas dúas metodoloxías en cuestión. A continuación, mostraremos un proxecto deseñado para a materia Modelos de interpretación literario-cultural nos países de fala inglesa (Cod. 4505106) do Mestrado Interuniversitario en Estudos Ingleses Avanzados e as súas Aplicacións que se imparte na Facultade de Filoloxía, cun peso docente de 31,5 horas e 4,5 créditos ECTS. Neste caso, trátase de utilizar técnicas relacionadas con 
entornos persoais de aprendizaxe (PLE) para a selección, organización e creación de contidos dixitais incluídos na materia mencionada.

\section{DESCRICIÓN DA EXPERIENCIA}

A primeira parte da experiencia, como se indicou na introdución, levouse a cabo no Mestrado de Secundaria, e en particular na materia de Metodoloxía, que como o seu nome indica, se centra na presentación de diversas metodoloxías para 0 ensino-aprendizaxe de linguas estranxeiras. Para isto compaxínase a exposición da profesora coa do alumnado. Os e as estudantes, habitualmente entre 24 e 26 , divídense en oito grupos de tres ou catro membros, traballan sobre un enfoque metodolóxico que se inclúe nos contidos da materia e expóñeno ao resto da aula. 0 resto das metodoloxías vense na aula e a exposición faina a profesora. No caso dalgunha delas, a aprendizaxe cooperativa e a aula invertida ou flipped classroom, empregaranse estratexias e técnicas das mesmas para a súa aprendizaxe, como veremos a continuación. Canto a segunda parte da experiencia, que se explica no punto 2.3 desta sección, desenvolveuse na materia sobre Modelos de interpretación literario-cultural do Mestrado de Estudos Ingleses Avanzados para o estudio, creación e presentación de varios de ditos modelos na clase por parte do alumnado que neste caso traballou en parellas, xa que 0 número de estudantes é inferior, entre oito e dez na Universidade da Coruña, tendo en conta que neste mestrado participan tamén outros alumnos e alumnas que teñen docencia nas dúas universidades galegas restantes. Dase tamén a particularidade de que esta materia non só a cursa alumnado do Mestrado, senon tamén estudantes do Programa de Doutoramento Interuniversitario en Estudos Ingleses Avanzados, no caso de que teñan que cursar complementos de formación.

\subsection{APRENDIZAXE COOPERATIVA}

Canto a aprendizaxe cooperativa, o que define este método é o uso sistemático de técnicas e estratexias grupais no ensino, como unha alternativa ás practicas do modelo de aula centrada 
no profesor/a (Richard e Rodgers, 2015). Neste sentido Johnson, Johnson e Smith (1998) indican que a diferencia da aprendizaxe competitiva e individualista, 0 alumnado pode traballar conxuntamente de xeito cooperativo para acadar obxectivos comúns. Cada estudante acada 0 seu obxectivo se e só se os outros e outras integrantes do grupo acadan os seus. 0 alumnado traballa en pequenos grupos para garantir que os e as membros do grupo acadan un criterio mínimo preestablecido.

Os elementos chave para o éxito do traballo en grupo nesta metodoloxía son:

- A interdependencia positiva: os e as membros dos grupos senten que 0 que axuda a un ou unha deles axuda a todos e todas.

- A responsabilidade individual: inclúe 0 rendemento grupal e individual, xa que cada membro do grupo ten un rol diferente no cumprimento dunha tarefa determinada.

- A interacción grupal cara a cara: para resolver unha tarefa os e as membros de grupo teñen que interactuar mediante explicacións, exposicións e debates.

- As habilidades sociais: 0 liderado, a toma de decisións, o fomento da confianza, a comunicación e a resolución de conflitos son habilidades que se practican con tanta resolución e precisión como as académicas.

- 0 procesamento grupal: identifícanse formas de mellorar os procesos que os e as integrantes dos grupos veñen utilizando para maximizar o súa propia aprendizaxe e a dos demais.

Ao tratarse dun Mestrado sobre ensino-aprendizaxe de linguas estranxeiras, o traballo en grupo que se propón neste método ofrece aos e ás estudantes a posibilidade de comunicarse na lingua estranxeira na aula. Richard e Rodgers (2015) expoñen de forma máis detallada os beneficios que aporta esta metodoloxía neste ámbito:

- Brinda oportunidades para a adquisición de forma natural dunha lingua estranxeira co uso de actividades interactivas en parella e grupo. 
- Proporciona aos docentes unha metodoloxía que lles permite acadar a comunicación entre os e as estudantes e que pode aplicarse nunha gran variedade de contornos curriculares.

- Permite unha atención centrada nos elementos léxicos, nas estruturas da lingua e nas funcións comunicativas mediante 0 uso de tarefas interactivas.

- Ofrece situacións nas que o alumnado pode desenvolver estratexias de éxito na aprendizaxe e a comunicación.

- Mellora a motivación dos alumnos e alumnas e reduce o seu estrés, á vez que se crea un clima afectivo positivo na aula.

Algunhas das técnicas empregadas nas aulas foron:

- Think-Pair-Share (Lyman, 1992, en Jacobs, 2006): Os e as estudantes traballan individualmente, cunha parella, tórnanse para falar, e comparten cos demais o que debateron.

- Write-Pair-Share (Kagan, 1992, en Jacobs, 2006), que é similar á anterior, pero en vez de facelo oralmente, faise de forma escrita.

- Jigsaw (Aronson, Blaney, Stephan, Sikes \& Sanpp, 1978, en Jacobs, 2006), que se desenvolve do seguinte modo:

- Os e as estudantes comezan no seu equipo local. Cada membro do equipo local recibe información sobre unha parte dun tema xeral

- 0 alumnado forma equipos de expertos cun pequeno número de compañeiros e compañeiras de clase para estudar a súa parte do tema e prepararse para ensinalo aos demais integrantes do seu equipo.

- Os e as estudantes regresan aos seus equipos de orixe e ensinan aos seus compañeiros e compañeiras de grupo.

- Todo o alumnado realiza unha proba ou traballa de forma conxunta nunha tarefa que inclúa todas as partes do tema. 


\subsection{AULA INVERTIDA OU FLIPPED CLASSROOM}

Como coa metodoloxía anterior, neste caso se utilizaron tamén as estratexias ou fases do enfoque para que 0 alumnado se familiarizase con el. En primeiro lugar, diremos que se trata dun enfoque pedagóxico no que a instrución directa se move dende o espazo de aprendizaxe grupal na aula ao espazo de aprendizaxe individual na casa, e o espazo grupal resultante transfórmase nun entorno de aprendizaxe dinámico e interactivo onde o docente guía aos e ás estudantes a medida que aplican conceptos e participan dun modo creativo no contido (Flipped Learning Network, 2014a). Polo tanto, elementos esenciais deste método son os materiais para traballar e analizar na casa e as tecnoloxías da información e comunicación (TICs) (Szyszka, 2015).

Segundo a Flipped Learning Network (2014b), os catro pilares do FLIP, utilizando este nome en inglés como acrónimo, son:

- F for flexibility: a flexibilidade abarca os espazos, as expectativas, as metodoloxías, a avaliación, etc., é dicir, todo o proceso de ensino-aprendizaxe.

- L for learning culture: trátase dun enfoque centrado no alumnado, polo que a aprendizaxe é activa e significativa.

- I for intentional content: os instructores e instructoras están continuamente a pensar en como 0 estudantado pode acceder mellor aos contidos (como crear o seleccionar contidos relevantes: gravación de vídeo e audio, páxinas web, simulacións, lecturas, etc.)

- P for professional educator: o rol do profesorado é incluso máis importante que nos métodos tradicionais, non só polo dito anteriormente, sino tamén porque na aula os e as docentes están continuamente observando, avaliando e dando feedback ao alumnado.

Como na metodoloxía anterior, os beneficios da flipped classroom para a aula de ensinoaprendizaxe de linguas estranxeiras son considerables (Basal, 2015; Chilingaryan e Szereva, 2017):

- Cada alumno ou alumna aprende a o seu propio ritmo.

- Supéranse as limitacións do tempo de clase. 
- A participación aumenta

- Proporciona máis oportunidades de aprendizaxe personalizada.

- Ofrece máis oportunidades para unha aprendizaxe centrada no alumnado.

- Unha conexión máis estreita entre alumnado e profesorado.

- Aumenta a motivación do alumnado.

- Mellora 0 ambiente na aula.

- Increméntase a creatividade e o pensamento crítico dos e das estudantes.

Para a implementación práctica desta metodoloxía na aula utilizouse o modelo de flipped classroom proposto por Jackie Gerstein (s.f.) na súa páxina web para o ensino superior con catro fases que se describen de forma gráfica na seguinte imaxe (imaxe 1):

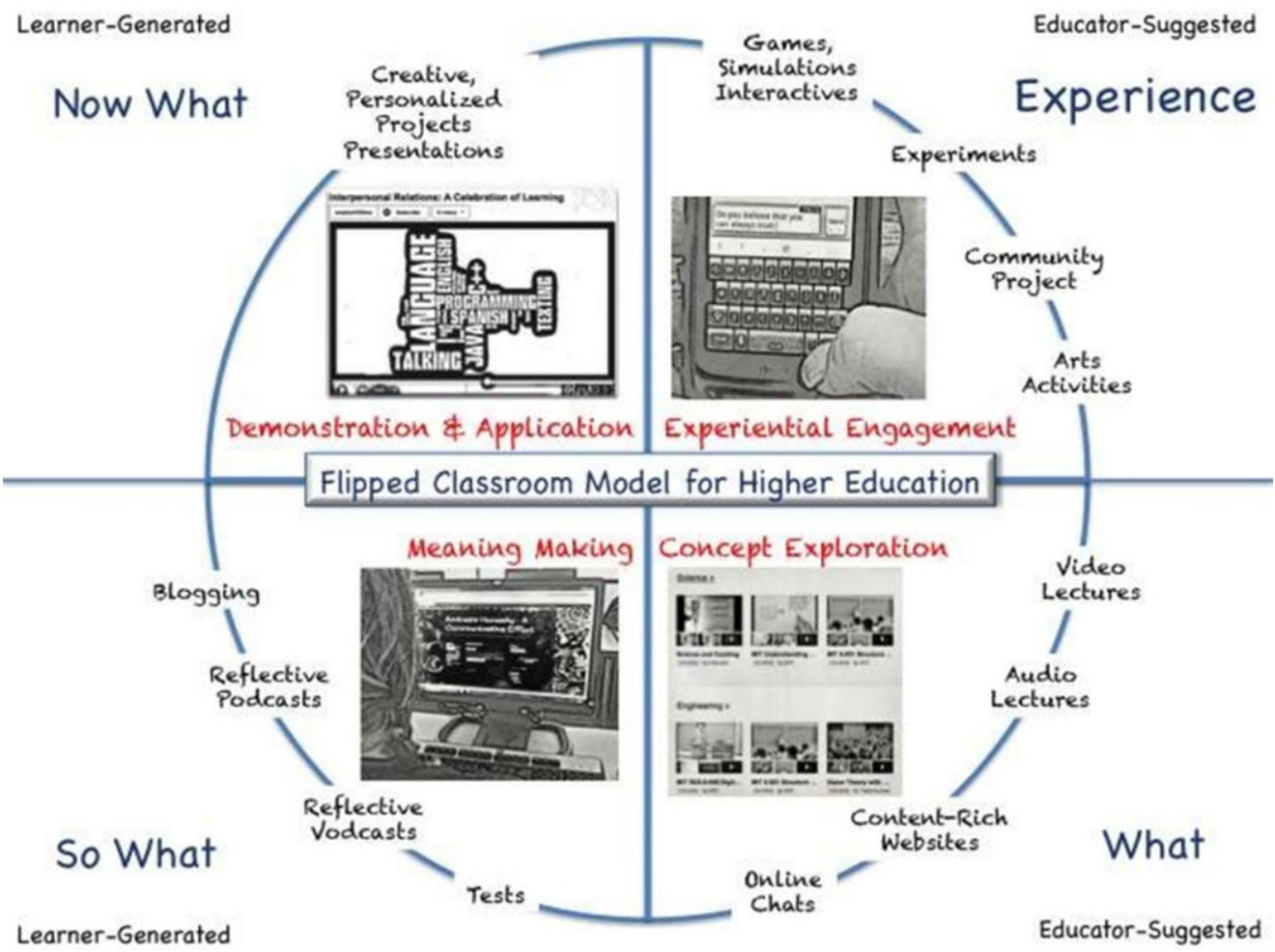

Imaxe 1: Modelo de flipped classroom de Jackie Gerstein. Fuente: https://cutt.ly/KrTKvUU 
Polo tanto a actividade realizada para que 0 alumnado coñecese esta metodoloxía foi realizada tamén en catro pasos:

1. Atraer a atención do alumnado a través dun vídeo da plataforma youtube, no que de forma entusiasta 0 profesor Jon Bergmann explica a necesidade dun cambio nas aulas: https://www.youtube.com/watch?time_continue $=1 \& v=$ RwKhZFZwkmE

2. Mediante vídeos online e páxinas web interesantes sobre flipped classroom, 0 alumnado coñecerá este método de forma individual na súa casa

3. Para que o alumnado cree o seu propio significado co material proporcionado, se utilizarán recursos online como podcasts, cuestionarios, discusións online ou blogues que tamén realizarán na casa (Institute for Teaching and Learning Innovation, s.f.). 0 alumnado poderá así compartir as súas reaccións co docente e cos seus compañeiros e compañeiras.

4. Xa na aula o alumnado, unha vez xa está familiarizado co método e como se debe implementar, deseñará unha proposta didáctica de lingua estranxeira para estudantes de Educación Secundaria baseada na flipped classroom ou aula invertida.

Finalmente, para avaliar esta actividade utilizaremos unha rúbrica mediante a que os grupos se avaliarán uns a outros, fomentando así a avaliación por pares.

\subsection{ENTORNOS PERSOAIS DE APRENDIZAXE (PLE)}

Entre as definicións do PLE, utilizando o acrónimo do termo en inglés (Personal Learning Environment), vemos que os diferentes autores empregan termos como servizo, sistema ou ferramenta. Así, Lubensky (2006) describe o PLE como un servizo para que os individuos poidan acceder, agregar, configurar e manipular artefactos ou ferramentas dixitais para as súas experiencias de aprendizaxe continua. Van Harmelen (2006), pola súa banda, incorpora 0 xiro educativo, cando di que os PLEs son sistemas que axudan aos e ás aprendices a tomar 0 control da súa propia aprendizaxe e xestionala. Isto inclúe dar ao alumnado 0 apoio para: establecer as súas propias metas de aprendizaxe, xestionar a súa aprendizaxe, tanto 0 contido 
como 0 proceso, comunicarse con outros durante 0 proceso de aprendizaxe e consecuentemente acadar os obxectivos propostos. De forma máis clara, Adell e Castañeda (2010) o describen como un conxunto de ferramentas, fontes de información, conexións e actividades que cada persoa utiliza de forma asidua para aprender.

En calquera caso, as súas vantaxes didácticas son importantes (Panagiotidis, 2012):

- Os PLEs ofrecen contornos de aprendizaxe máis ricos e manteñen 0 interese do alumnado durante máis tempo.

- En canto ao ensino-aprendizaxe de linguas, poden axudar aos e ás estudantes a achegarse á lingua e aos seus falantes de forma máis sinxela que cos sistemas tradicionais.

- Os PLEs poden promover diversas prácticas educativas, tanto formais como informais, e favorecer moitos obxectivos de alfabetización informacional como:

- a selección de fontes,

- a creación de estratexias de procura efectivas

- unha mellor comprensión da información en torno a un tema específico, a través da variedade de fontes que poden concentrarse nun espazo común

Para o noso obxectivo, que é 0 análise e exposición en grupos de varios enfoques críticos actuais, resulta de interese a relación que establece Álvarez Jiménez (2014) entre o PLE e a resolución de problemas, pois indica que o PLE e unha combinación híbrida de dispositivos, aplicacións, servizos e redes persoais que empregamos para adquirir de forma autónoma novas competencias para a resolución de problemas. Propón seis áreas de actuación: 1) Procura de información, 2) Filtrado da información relevante, 3) Organización da información seleccionada, 4) Xeración de contidos dixitais, 5) Compartir contidos en rede, 6) Participación e comunicación en comunidades.

Seguindo estas áreas, a actividade que se propón para esta materia en concreto divídese en dúas partes e realizarase en parellas. A primeira parte comprende as tres primeiras áreas mencionadas e desenvólvese do seguinte modo: 
1. Tendo en conta os contidos que se tratan nesta materia, 0 alumnado deberá seleccionar ferramentas e servizos de información relacionados con aspectos teóricos sobre enfoques críticos actuais, como o multiculturalismo, a etnocrítica, os estudos postcoloniais, a diáspora e transnacionalismo 0 a ecocrítica.

2. A continuación, filtrarán a información que lles resulte máis relevante.

3. Finalmente, organizarano todo, e para isto sería interesante que utilizaran, por exemplo, o escritorio symbaloo.

Na segunda parte, serán as outras tres áreas as que se leven a cabo:

4. En primeiro lugar, terán que xerar algún contido dixital. Cada unha das parellas centrarase nun dos enfoques para elaborar unha presentación en PPT, Prezzi, ou similar, na que expliquen en que consiste, as súas características e como utilízalo para a análise de textos. Farano de forma cooperativa utilizando, por exemplo, PPT en Google Drive ou Onedrive.

5. A continuación, compartirán este contido co resto da aula. Para isto utilizarase Google classroom. Crearemos unha clase para o noso curso e subirán as súas presentacións para que o resto do alumnado teña acceso a elas. Tamén se lles dará a posibilidade de que cren unha conta de Twitter, por exemplo, se queren compartir estes contidos cunha comunidade máis ampla.

6. Por último, o terceiro obxectivo deste bloque, referido á comunicación en rede, utilizarémolo como instrumento de avaliación. En concreto serán os e as estudantes os que levarán a cabo a avaliación do traballo realizado polos seus compañeiros e compañeiras. Polo tanto, utilizaremos a avaliación por pares, aínda que tamén podemos implementar a autoavaliación no caso de que queiramos que cada parella se avalíe a se mesma. 


\section{RESULTADOS E CONCLUSIÓNS}

En primeiro lugar, un dos aspectos que queríamos salientar neste traballo é que cando a materia que se imparte trata sobre metodoloxía, como así ocorre nunha das materias mencionadas, a incorporación dun enfoque práctico é moi necesaria, dado que o alumnado pode experimentar de primeira man os aspectos básicos do método que se está a estudar. De feito as dúa metodoloxías que se traballaron na materia do Mestrado de Secundaria, a aprendizaxe cooperativa e a aula invertida, son moi sinxelas de abordar de xeito práctico na aula, como se pode comprobar neste estudo. Por outra banda, tanto a flipped classroom como os PLEs son enfoques metodolóxicos que implican a utilización de ferramentas TIC na aula, e aínda que 0 noso alumnado pode ser considerado como milenial ou nativo dixital, non está acostumado a utilizar estas novas tecnoloxías como recursos de ensino-aprendizaxe, e con esta proposta poderán facelo. Finalmente, queríamos poñer de relevo que mediante a actividade que presentamos para traballar contidos a través de PLEs, os e as estudantes tamén desenvolven habilidades de alfabetización informacional, e conciéncianse de que da información que teñen dispoñible na Internet non todo vale, á vez que se sensibilizan e reflexionan sobre a súa propia aportación ao mundo online, e como facelo de forma apropiada e responsable.

Outro dos atractivos deste tipo de metodoloxías activas proven do seu énfase no traballo en grupo e en parellas, que resulta tremendamente beneficioso nas materias de linguas estranxeiras, xa que promoven a comunicación entre os e as estudantes na lingua meta, un compoñente que agradecen moito. Tamén móstranse moi interesados no traballo práctico na aula, posto que nos mestrados nos que se implementaron estas propostas as sesións son habitualmente de tres horas pola tarde e resúltalles máis levadero. Por outra banda, e isto é quizais 0 máis interesante desta experiencia, os propios alumnos e alumnas mostraron interese por utilizar eles e elas estas estratexias durante as súas prácticas nos centros educativos, e así o mostraron nas súas memorias do Practicum. Igualmente, nos Traballos Fin de Mestrado incorporaron técnicas e actividades que previamente realizaran eles e elas nas materias do Mestrado. 


\section{REFERENCIAS}

Adell, J. \& Castañeda, L. (2010). Los Entornos Personales de Aprendizaje (PLE): una nueva manera de entender el aprendizaje. En R. Roig-Vila \& M. Fiorucci (Eds.), Claves para la investigación en innovación y calidad educativas. La integración de las Tecnologías de la Información y la Comunicación y la Interculturalidad en las aulas / Stumenti di ricerca per l'innovaziones e la qualità in ámbito educativo. La Tecnologie dell'informazione e della Comunicaziones e l'interculturalità nella scuola (pp. 19-30). Alcoy: Marfil e Università degli Studi Roma TRE.

Álvarez Jiménez, D. (2014). PLE: Aprendizaje conectado en red. Madrid: Instituto Nacional de Tecnologías Educativas y de Formación del Profesorado (INTEF).

Basal, A. (2015). The Implementation of a Flipped Classroom in Foreign Language Teaching. Turkish Online Journal of Distance Education-TOJDE, 16 (4), 28-37.

Chilingaryan, K. \& Zvereva, E. (2017). Methodology of Flipped Classroom as a Learning Technology in Foreign Language Teaching. 7th International Conference on Intercultural Education "Education, Health and ICT for a Transcultural World", Procedia - Social and Behavioral Sciences, 237,1500-1504

Flipped Learning Network (2014a). What is Flipped Learning? https://flippedlearning.org/wpcontent/uploads/2016/07/FLIP_handout_FNL_Web.pdf

--- (2014b) The Four Pillars of F-L-I-P. https://flippedlearning.org/wp-content/uploads/2016/07/ FLIP_handout_FNL_Web.pdf

Gerstein, J. (s.f.). Flipped Classroom: The Full Picture https://www.theflippedclassroom.es/ jackie-gerstein-flipped-classroom-the-full-picture/

Institute for Teaching and Learning Innovation (s.f.). About Flipped Classrooms. What is the 'flipped classroom'? http://www.uq.edu.au/teach/flipped-classroom/what-is-fc.html Jacobs, G.M. (2006). Cooperative Learning Techniques and Activities. En S. McCafferty, G.M. Jacobs \& A.C. DaSilva Iddings (Eds.), Cooperative Learning and Second Language Teaching (pp. 181-196). Cambridge: Cambridge University Press. 
Johnson, D., Johnson. R. \& Holubec, E. (1994). Cooperative Learning in the Classroom. Alexandria VA: Association for Supervision \& Curriculum.

Johnson, D., Johnson, R. \& Smith, K. (1998). Cooperative Learning Returns to College: What Evidence Is There That It Works? Change, 30(4), 27-35.

Lubensky, R. (2006). The Present and Future of Personal Learning Environments (PLE). http://www.360doc.com/content/07/1213/21/50534_892566.shtml

McLaren, N. \& Madrid, D. (2005). The FL teacher and Class Management. En N. McLaren, D. Madrid \& A. Bueno (Eds.), TEFL in Secondary Education (pp. 211-240). Granada: Universidad de Granada.

Panagiotidis, P. (2012). Personal Learning Environments for Language Learning. Socialinés Technologijos / Social Technologies, 2(2), 420-440.

Richards, J. \& Rodgers, T. (2015). Approaches and Methods in Language Teaching, $2^{\mathrm{a}}$ ed. Cambridge: Cambridge University Press.

Szyszka, M. (2015). Multimedia in Learning English as a Foreign Language as Preferred by German, Spanish, and Polish Teenagers. En L. Piasecka, M. Adams-Tukiendorf \& P. Wilk (Eds.), New Media and Perennial Problems in Foreign Language Learning and Teaching (pp. 189-207). Heidelberg: Springer.

Ur, P. (2015). A Course in English Language Teaching. $2^{\mathrm{a}}$ ed. Cambridge: Cambridge University Press.

Van Harmelen, M. (2006). Personal Learning Environments. En Proceedings of the Sixth International Conference on Advanced Learning Technologies (ICALT06). http://citeseerx.ist.psu.edu/viewdoc/download?doi=10.1.1.97.2772\&rep =rep1\&type = pdf 